\title{
COnE)-(OES
}

CIÊNCIA E TECNOLOGIA

\section{APLICAÇÃO DE CONVERSOR ELETRÔNICO DE ALTO RENDIMENTO PARA BOMBEAMENTO SOLAR FOTOVOLTAICO SEM BATERIAS}

\author{
José Rogério Maciel Ferreira Filho ${ }^{1}$, Igor Rocha de SousA ${ }^{1}$, \\ Cláudio Marques de SÁ Medeiros ${ }^{1}$ \\ ${ }^{1}$ Instituto Federal de Educação, Ciência e Tecnologia do Ceará - IFCE \\ <jrmff@yahoo.com.br><igor.sousa.sousa@hotmail.com><claudiosa@ifce.edu.br> \\ DOI: <https://doi.org/10.21439/conexoes.v14i3.1467>
}

\begin{abstract}
Resumo. Neste trabalho é sugerido um sistema de bombeamento solar fotovoltaico (FV) autônomo sem o uso de baterias e composto de painéis FV, conversor CC-CC boost de alto ganho de tensão, baseado na célula de comutação de três estados (AGTCCTE), conversor CC-CA de frequência variável e motobomba submersa. Com a utilização do conversor CC-CC boost AGT-CCTE, é possível realizar a adequação de potência entre os painéis FV e o conversor CC-CA reduzindo assim o número de painéis FV utilizados. Através de ensaios experimentais verifica-se o comportamento do conversor CC-CC boost AGT-CCTE diante de situações distintas de operação, possibilitando a avaliação do desempenho do mesmo. Com os resultados experimentaisé observado que o conversor boost utilizado apresenta um rendimento de 92,52 \%. Durante os períodos de máxima irradiância o sistema de bombeamento apresenta uma vazão máxima de $1100 \mathrm{l} / \mathrm{h}$ a uma altura manométrica de $25 \mathrm{~m}$.
\end{abstract}

Palavras-chaves: Bombeamento de água. Controlador digital. Conversor boost. Painel fotovoltaico.

\begin{abstract}
In this work it is suggested a system of pumping solar photovoltaic (PV) without the use of batteries and composed of PV panels, boost DC-DC converter, based on the three-state commutation cell, variable frequency drive and submersible motor pump. With the use of the boost DC-DC converter based on the three-state commutation cell, it is possible to perform the power adjustment between the PV panels and the DC-AC converter, thus reducing the number of PV panels used. Through experimental tests, the boost DC-DC converter based on the three-state commutation cell behavior in different situations of operation is verified, allowing the evaluation of the performance of the same. With the results experimental data, it is observed that the boost DC-DC converter based on the three-state commutation cell present efficiency of $92.52 \%$. During periods of maximum irradiation, the pumping system has a maximum flow of $1100 \mathrm{l} / \mathrm{h}$ in the head of $25 \mathrm{~m}$.
\end{abstract}

Keywords: Water pumping. Digital controller. Boost converter. Photovoltaic panel.

\section{INTRODUÇÃO}

Muitas comunidades não dispõem de água para consumo próprio ou para irrigação e uso animal. Com a ausência de água superficial, essas comunidades vivem sem perspectiva de crescimento e fonte de renda, mesmo tendo disponíveis aquíferos subterrâneos com abundância de água de qualidade (SILVA, 2014).

Com a crescente utilização de energia solar fotovoltaica (DOLJAK; POPOVIĆ; KUZMANOVIĆ, 2017), a lenta porém crescente evolução tecnológica dos materiais semicondutores aplicados à células fotovoltaicas (WANDERLEY, 2013) e o fato de regiões como o Ceará possuírem uma alta insolação, com cerca de 2550 horas de irradiação solar anuais (ANEEL, 2005), o uso da energia elétrica proveniente da irradiação do sol para a realização do bombeamento torna-se bastante atrativo. Assim, o agricultor do campo pode utilizar a água para irrigação, consumo animal e próprio, me- 
lhorando a qualidade de vida e possibilitando maiores retornos financeiros, reduzindo impactos ambientais e sociais (SILVA, 2014).

Segundo Green et al. (2015), Boutelhig e Bakelli (2012), os painéis fotovoltaicos de silício possuem rendimento entre $10,5 \%$ e $25,6 \%$ e operam por um período limitado de horas durante o dia. Por isso é necessário aproveitar ao máximo a energia gerada pelos mesmos. Dessa forma é interessante diminuir as perdas entre a geração de energia e o sistema de bombeamento através da utilização de dispositivos eletrônicos mais eficientes. Muitas propostas de sistemas de bombeamento incluem a utilização de baterias. Apesar do sistema ficar independente de oscilações naturais de irradiância devido a passagem de nuvens, o custo elevado das baterias, aliada à sua relativa baixa durabilidade, inviabilizam a aplicação em comunidades carentes.

Diversos sistemas de bombeamento são propostos uutilizando painéis fotovoltaicos. Entre eles, pode-se destacar Taha e Suresh (1996), Brito e Zilles (2006), Muljadi e Taylor (1996), que fazem a interface de alimentação conectando um conjunto de painéis fotovoltaicos em série diretamente no barramento $\mathrm{CC}$ de um conversor de frequência. No entanto, esta técnica necessita de um elevado número de painéis, visto que se necessita igualar a tensão do barramento $\mathrm{CC}$ ao valor de pico da onda de tensão de alimentação nominal do conjunto motor-bomba. Outra desvantagem é a necessidade de uma grande área, sem sombreamento, para a instalação dos painéis.

Bhat, Pittet e Sonde (1987), Dessouky et al. (2016) conectaram os painéis fotovoltaicos a um conversor CC-CC tipo boost supervisionado por um algoritmo MPPT e conectado a um conversor CC-CA para a alimentação de um motor de indução trifásico acoplado a uma bomba. Porém, os autores destes trabalhos não relatam informações de eficiência do sistema, principalmente do conversor CC-CC boost.

Diante dos trabalhos anteriores, o presente trabalho apresenta uma solução para o bombeamento de água para agricultura doméstica e irrigação de pequenas culturas. A energia primária provida do sol é convertida para energia elétrica através de painéis fotovoltaicos, que são conectados à um conversor de $1 \mathrm{~kW}$ tipo boost de alto desempenho (acima de 93\% (SILVEIRA et al., 2014)) e alto ganho estático que fornece tensão regulada a um conversor de frequência ao mesmo tempo que elimina a grande quantidade de painéis que seria exigido em uma ligação em série. Este conversor de frequência, por sua vez, aciona um conjunto motor-bomba equipado com motor de indução trifásico e bomba centrí- fuga submersa.

\section{Metodologia}

Neste trabalho, é desenvolvido um protótipo de sistema de bombeamento. Por esse motivo, optou-se por usar painéis fotovoltaicos e por não usar baterias. Além disso, o conjunto motor-bomba utilizado também segue a ideia de grande robustez e baixos requisitos de manutenção. A forma de armazenagem de energia do sistema é através da energia potencial gravitacional, em que a água bombeada é elevada e armazenada em uma caixa d'água, possibilitando dessa formaa utilização da água nos momentos de baixa irradiância. De forma a exemplificar o sistema é ilustrado na Figura 1 o diagrama esquemático proposto. A seguir, é abordado cada componente utilizado no sistema.

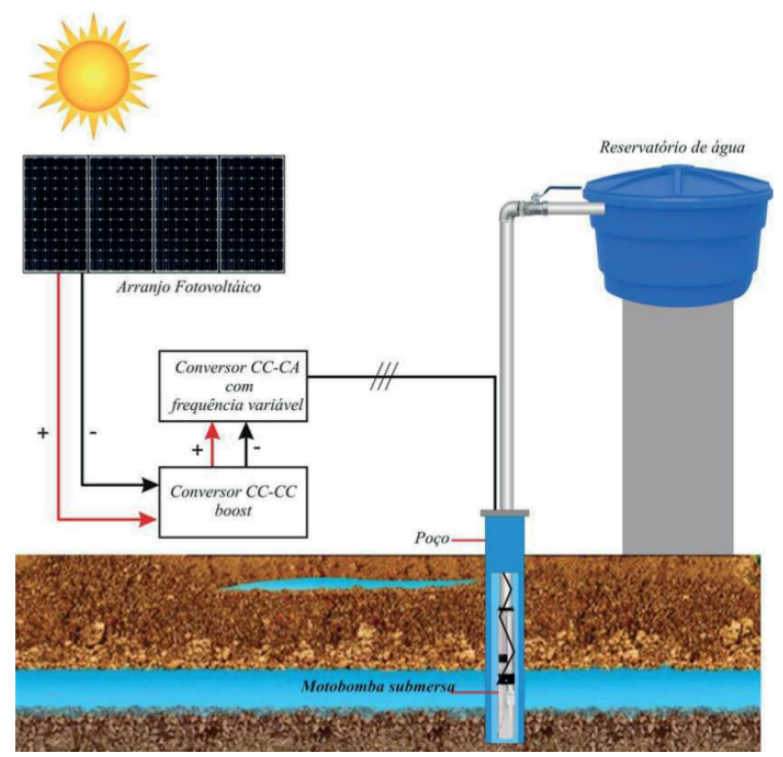

Figura 1: Diagrama esquemático do sistema proposto.

\subsection{Painéis fotovoltaicos}

Para o estudo, são utilizados como fonte de alimentação primária, quatro painéis fotovoltaicos SunEdison P-Series-265 W, sendo cada um composto de 60 células fotovoltaicas. $\mathrm{O}$ arranjo é composto por 2 painéis ligados em série em paralelo com os outros 2 painéis, de forma a se obter tensão e corrente no ponto de máxima potência $(1060 \mathrm{~W})$ em $61,42 \mathrm{~V}$ e $17,26 \mathrm{~A}$.

É realizada uma a valiação do desempenho dos painéis fotovoltaicos através de ensaios realizados em condições reais de temperatura e irradiância, e são compa- 
rados com os dados fornecidos pelo fabricante. Os ensaios são realizados impondo variações no valor da resistência em reostatos de potência. Os reostatos são interligados aos terminais do painel $\mathrm{FV}$, e para cada valor de resistência imposta, são medidos os valores de tensão, corrente e temperatura do painel FV. Os ensaios são realizados com o painel interligado à carga por condutores de $2,5 \mathrm{~mm}^{2}$ e $6 \mathrm{~mm}^{2}$. Com o intuito de averiguar a influência da temperatura sobre a potência fornecida, é realizado um arrefecimento com lâmina de água corrente na superfície superior do painel. Para realizar a comparação entre os ensaios, são utilizados os valores da folha de dados do fabricante como referência. As curvas do fabricante são obtidas por meio de simulação com o modelo de 1 diodo (LIU; HUANG, 2011). Na Figura 2 são ilustradas as curvas dos ensaios e da simulação com o modelo elétrico de um diodo de acordo com os dados do fabricante.
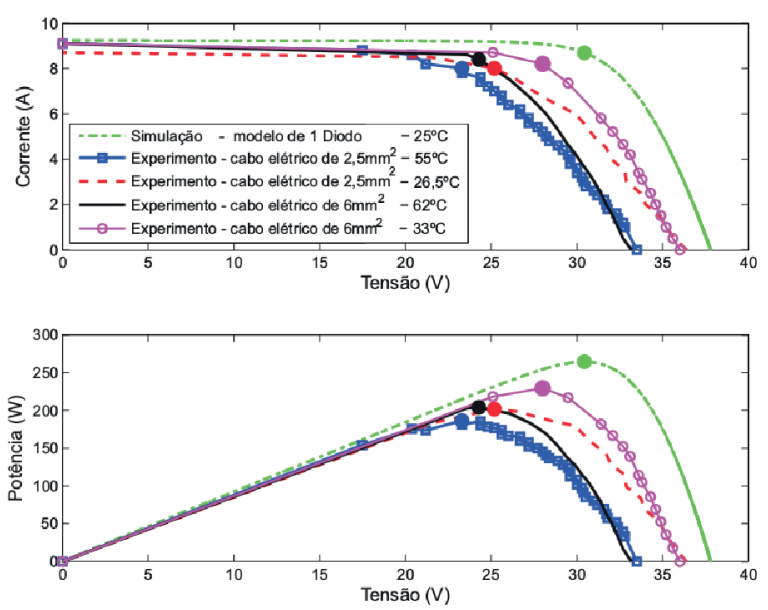

Figura 2: Curvas do painel FV SunEdison P-Series 265 W.

Percebe-se que a instalação de cabeamento inadequado (de 2,5 $\mathrm{mm}^{2}$ ) e o efeito da temperatura do painel FV influenciam na potência fornecida. Diante dos resultados conclui-se que, mesmo utilizando os cabos elétricos de $6 \mathrm{~mm}^{2}$ e os conectores MC4, recomendados pelo fabricante do painel $\mathrm{FV}$, a temperatura do mesmo em condição operacional local $\left(62^{\circ} \mathrm{C}\right)$ limita a potência disponível a $204,1 \mathrm{~W}$, o que corresponde a $77,01 \%$ da potência de pico.

\subsection{Conversor de frequência}

Para realizar o acionamento do conjunto motorbomba, é necessário alterar sua rotação durante as variações de irradiância e realizar uma estratégia de partida suave do motor, evitando assim as altas correntes solicitadas durante partidas diretas convencionais. Dessa forma, optou-se pelo uso de um conversor de frequência da marca WEG, modelo CFW-08, com entrada monofásica $220 \mathrm{~V}$ eficaz e saída trifásica de $220 \mathrm{~V}$ eficaz de linha. Neste estudo, o conversor de frequência é alimentado diretamente com tensão CC de $311 \mathrm{~V}$ em seus terminais de entrada.

\subsection{Conjunto motor-bomba}

O conjunto motobomba utilizado é da marca DANCOR, modelo SPP-1.1-TSR-13 de treze estágios, acionada por um motor de indução trifásico de 2 pólos, 60 $\mathrm{Hz}, 3450 \mathrm{rpm}$, potência de $0,5 \mathrm{cv}$ e tensão nominal de $220 \mathrm{~V}$ eficaz de linha, sendo a mesma cedida pela empresa DANCOR para realização deste trabalho.

\subsection{Conversor CC-CC boost}

Para a determinação da topologia do conversor boost a ser utilizada, é levado em consideração que o acionamento da bomba é composto de um motor de indução trifásico com tensão nominal de $220 \mathrm{~V}$ eficaz. Sendo assim, é necessária a obtenção de uma tensão de pico $\left(\mathrm{V}_{\text {pico }}\right)$ de aproximadamente $311 \mathrm{~V}$, de forma a permitir que o conversor de frequência funcione de forma adequada.

Em Torrico-Bascopé et al. (2006) é proposta uma nova topologia para o conversor boost, visando a obtenção de um alto ganho de tensão baseado na célula de comutação de três estados. Para tanto, é aplicado um multiplicador de tensão com o objetivo de aumentar a tensão de saída.

Torrico-Bascopé et al. (2006), Alcazar et al. (2008), Pereira, Martins e Carvalho (2014), mencionam que a topologia apresenta um rendimento acima de 93\%. Diante dessa característica e do alto ganho estático fornecido pela estrutura do conversor, esta topologia vem sendo utilizada em diversos estudos, como Klimczak e Munk-Nielsen (2009), Alcazar et al. (2013), Alves et al. (2015).

Em Silveira et al. (2014) são utilizados dois enrolamentos secundários no conversor boost baseado na célula de comutação de três estados, permitindo assim a obtenção de um ganho estático $(\mathrm{G})$, descrito na Equação 1

$$
G=\frac{V_{o}}{V_{i n}}=\frac{1}{1-D}\left(1+\sum_{j=1}^{n} a\right)
$$


em que $V_{o}$ é a tensão de saída do conversor, $V_{i n}$ é a tensão de entrada, $D$ é a razão cíclica, $n$ é o número de secundários e $a$ é a relação primário-secundário do transformador. A nova estrutura possibilita um maior grau de amplificação do ganho, sendo este agora também influenciado pelo número de secundários aplicados na topologia. Na Figura 3, adaptada de Silveira et al. (2014), é ilustrada a nova estrutura para o conversor.

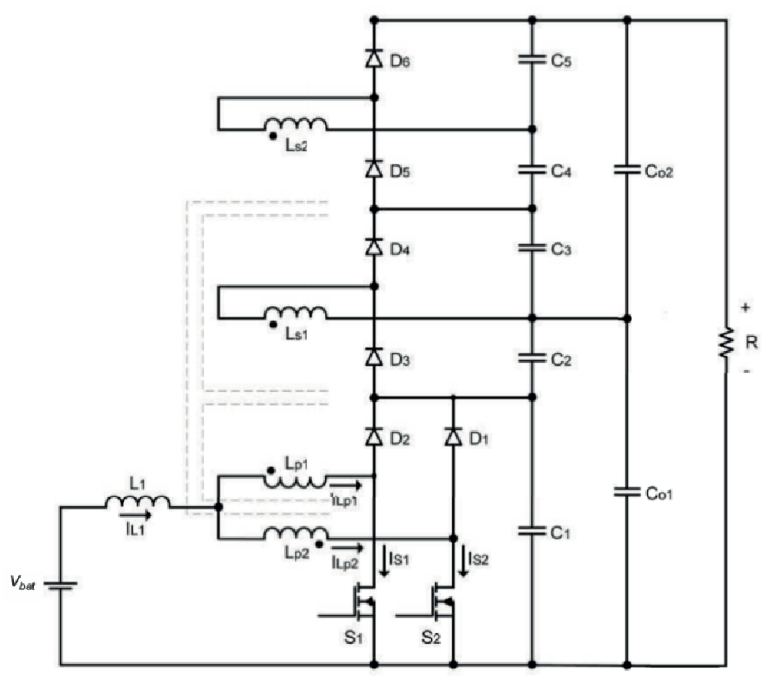

Figura 3: Conversor CC-CC boost AGT-CCTE com 2 secundários.

\subsection{Projeto do controlador de tensão do boost}

O controle do conversor boost é imprescindível uma vez que é preciso manter constante o valor de $311 \mathrm{~V}$ na entrada do conversor de frequência para que o conjunto motor-bomba possa ser alimentado. Sem o controle, essa tensão deve variar com a presença de nuvens sobre os painéis fotovoltaicos. Assim, o controle proposto é um Proporcional-Integrador (PI), que mantém a tensão regulada em $311 \mathrm{~V}$ diante de perturbações tais como elevação da temperatura de operação dos painéis ou sombreamentos parciais. Uma consequência direta dessa regulação é o aumento do desempenho do conversor de frequência e do conjunto motor-bomba.

O modelo representativo de um painel fotovoltaico inclui uma fonte de corrente. Assim a corrente do painel FV está limitada a sua corrente de curto-circuito, a qual, nesta aplicação, é inferior a suportada pelas chaves de potência e demais componentes do conversor. Dessa forma, optou-se por implementar apenas a malha de tensão no conversor.
Com o objetivo de encontrar uma representação matemática do conversor boost na forma de função de transferência que viabilize a aplicação de técnicas convencionais para o projeto do controlador digital, é proposta a utilização da técnica de Hammerstein para o conversor boost. Como pode ser observado na Figura 4, adaptada de Alonge et al. (2007), o modelo de Hammerstein é composto por uma não linearidade estática em cascata com um modelo dinâmico linear (AGUIRRE; COELHO; CORREA, 2005; ALONGE et al., 2015; BEZERRA, 2015).

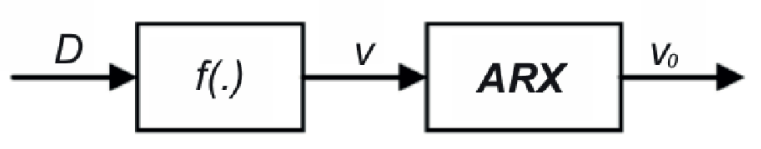

Figura 4: Representação do modelo de Hammestein.

A característica estática $f($.$) do conversor, foi ob-$ tida a partir de simulações computacionais e é representada na Equação 2,

$$
f(D)=0,1257 D^{2}-9,9145 D+356,0329
$$

enquanto que para o modelo dinâmico, o conversor boost foi submetido a uma tensão de entrada fixa de 30 V e subtemido um sinal PRAS (Pseudo Random Analog Signal) à entrada de razão cíclica. Posteriormente, foi aplicado o algoritmo dos mínimos quadrados com restrições (DRAPER, 1998) aos dados adquiridos, obtendo assim a função de transferência dada na Equação 3 ,

$$
G(z)=\frac{V_{o}(z)}{V_{i n}(z)}=\frac{0,07043}{z-0,9296}
$$

Na Figura 5 são apresentadas as respostas transitórias do conversor e do modelo de Hammerstein. O erro em regime permanente é $0,30 \%$, e a resposta transitória do modelo é julgada como satisfatória.

Adota-se um máximo sobressinal aceitável para projeto de $20 \%$ e um tempo de acomodação menor que 0,6 s. A função de transferência adotada para o controlador é composta de um polo, um zero e um ganho (K $=4,5$ ), conforme a função de transferência expressa por na Equação 4,

$$
G_{p i}(z)=K \frac{z-0,4}{z-1}
$$

O diagrama de blocos do sistema de controle de tensão é ilustrado na Figura 6, onde $G_{p i}(z)$ é a função de 


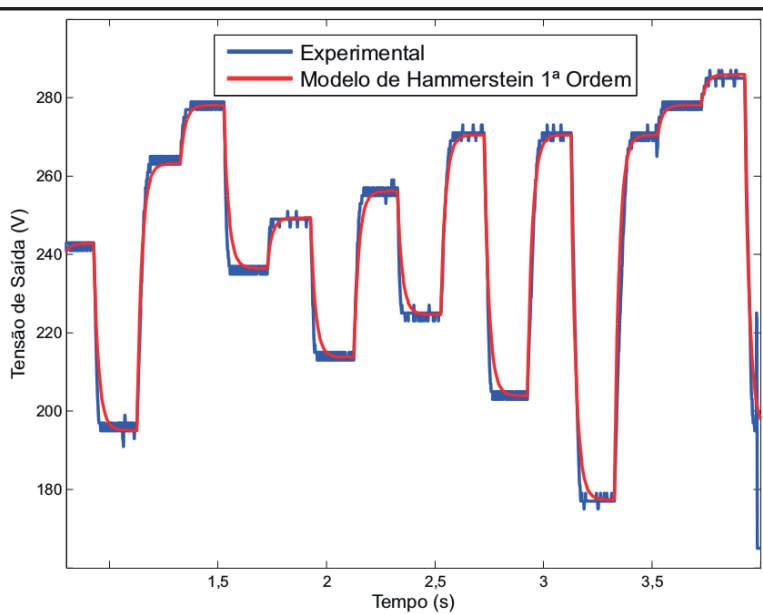

Figura 5: Comparativo entre o modelo de Hammerstein e o ensaio experimental.

transferência do boost e $H(z)$ o ganho do sensor de tensão utilizado para realimentar o sistema. O mesmo foi obtido com um divisor de tensão com resistores.

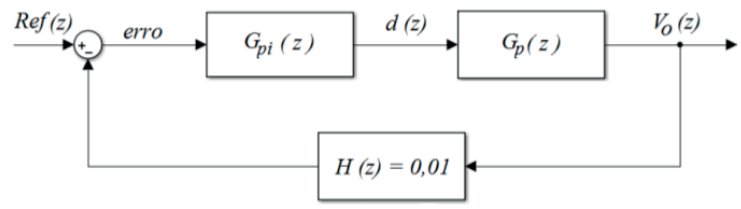

Figura 6: Diagrama de blocos do controle de tensão.

Para executar o controle do conversor boost e o comando de suas chaves, é utilizado o microcontrolador dsPIC30f4013 da Microchip. O mesmo também promove a proteção contra sobretensão do barramento $\mathrm{CC}$ de saída, evitando assim danos nos componentes por rompimento da rigidez dielétrica, e a proteção contra subtensão, para evitar o desligamento indevido do conversor de frequência. Além disso, o microcontrolador opera um sistema de monitoramento da tensão dos painéis fotovoltaicos que comunica ao conversor de frequência em que nível de velocidade o conjunto motor-bomba deve estar, de modo que o controlador não sature sua saída.

\subsection{Configuração do Sistema de Bombeamento}

Neste estudo, o conversor de frequência é alimentado com tensão de entrada igual a $311 V_{c c}$, proveniente da saída do conversor CC-CC boost AGT-CCTE.
O conversor de frequência é parametrizado para operar no modo de controle escalar linear, com a entrada analógica habilitada para receber a referência externa de frequência e a entrada digital para receber o comando de reset. O controlador é capaz de alterar a velocidade de operação do conjunto motobomba, permitindo desse modo a variação de carga aplicada na saída do conversor CC-CC boost AGT-CCTE. Dessa forma o conjunto motobomba pode ter sua velocidade reduzida sempre que ocorram momentos de baixa irradiância solar, evitando o desligamento e maximizando o tempo de funcionamento do sistema. Na Figura 7 é ilustrado o fluxograma das ações realizadas pelo controlador para o acionamento do conversor de frequência e proteção do conversor CC-CC boost AGT-CCTE.

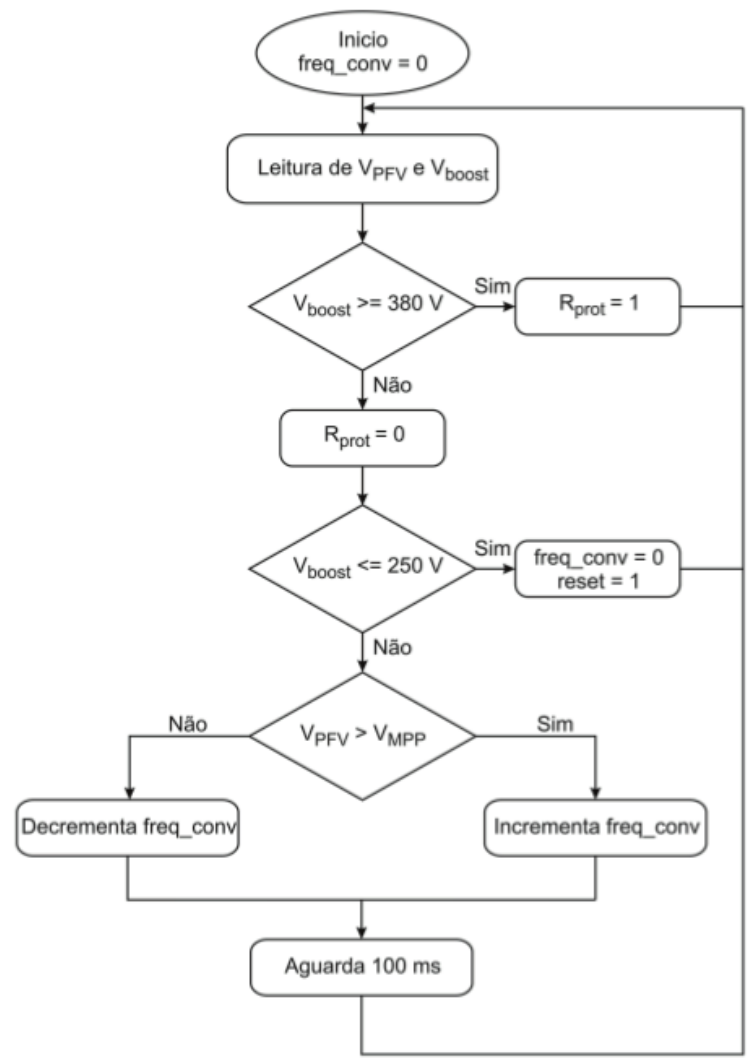

Figura 7: Fluxograma das funcionalidades do processador digital

Ao entrar em funcionamento o conversor boost eleva sua tensão de saída $\left(\mathrm{V}_{\text {boost }}\right)$ para 311 V. Em seguida a rotina de controle inicia o incremento de frequência (freq ${ }_{c o n v}$ ) via entrada analógica do conversor de frequência, impondo uma carga mais elevada ao arranjo fotovoltaico. Dessa forma, a tensão dos painéis 
FV $(V P F V)$ começa a reduzir. Quando a tensão está em $50 \mathrm{~V}$, a rotina de controle realiza a redução da carga aplicada para manter a operação próxima da tensão no ponto de máxima potência $(V M P P)$.

Devido a momentos de baixa irradiância promovidos pela passagem de nuvens, os painéis fotovoltaicos podem não fornecer as potências necessárias para manter a tensão de saída do conversor CC-CC boost AGTCCTE em 311 V. Se a tensão cair abaixo de $200 \mathrm{~V}$, o conversor de frequência (comercial) entra em modo de proteção por subtensão e se auto desliga. Para evitar o desligamento desnecessário do conversor de frequência, o sistema de controle reduz abruptamente a frequência comandada ao conversor de frequência sempre que a tensão de saída do conversor CC-CC boost AGT-CCTE cair abaixo de $250 \mathrm{~V}$, para aumentar a margem de segurança. Caso o desligamento seja inevitável, a rotina de controle envia um comando digital de reset para o conversor de frequência com o intuito de reiniciar a operação.

\section{Resultados}

Na Figura 8 são ilustradas as curvas de tensão de saída e tensão de alimentação do conversor CC-CC boost AGT-CCTE. Para esse ensaio são impostas variações de $10 \mathrm{~V}$ na tensão de alimentação do conversor, com o objetivo de emular as variações de tensão impostas pelos painéis FV durante as variações de irradiância. Portanto, observa-se que a tensão de saída manteve-se dentro da faixa estipulada no projeto do controlador, apresentando neste ensaio um afundamento de 2,9\% e um sobressinal máximo de 3,6 \% na tensão de saída do conversor.

O ensaio prático de bombeamento foi realizado com o objetivo de analisar o desempenho do sistema. Neste ensaio, a placa de controle inicia a partida do conjunto motobomba, realizando incrementos de frequência por meio da entrada analógica do conversor de frequência, conforme detalhado anteriormente.

Na Figura 9, observa-se que inicialmente a tensão fornecida pelo arranjo FV é de $58 \mathrm{~V}$. Com o intuito de aumentar a vazão do conjunto motobomba a partir do instante $t=360 \mathrm{~s}$, são realizados incrementos na frequência comandada no conversor de frequência elevando assim a potência consumida pelo sistema. Isto faz com que a tensão do arranjo FV seja reduzida. Neste teste a tensão do arranjo FV sofre uma variação máxima de 8,55 V. Da mesma forma que no teste de bancada, conclui-se que o controlador mantem a tensão no barramento CC estabilizada mesmo diante das variações na sua tensão de alimentação, não possuindo sobressinal

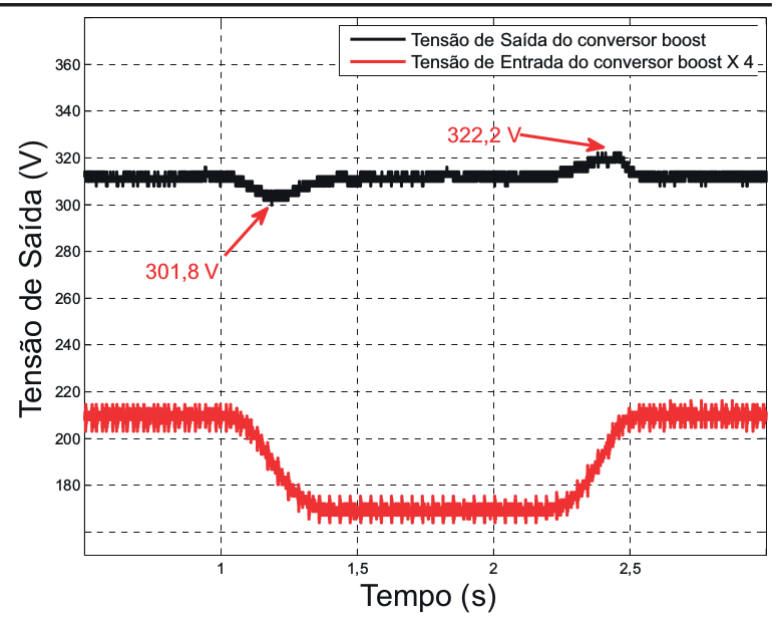

Figura 8: Comportamento da tensão de saída para variações na tensão de alimentação.

ou afundamentos na tensão de saída do conversor CCCC boost AGT-CCTE.
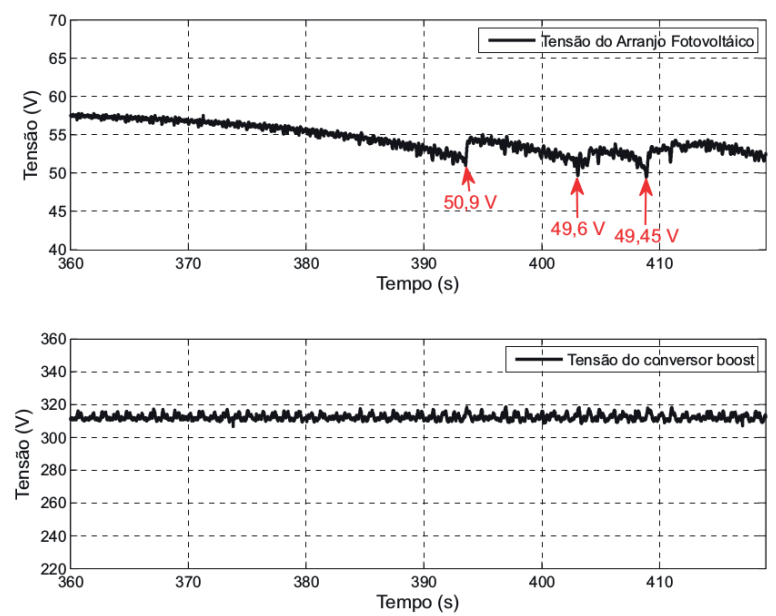

Figura 9: Comportamento da tensão de saída do conversor CC-CC boost AGT-CCTE diante de uma variação na carga.

Na Figura 10 é ilustrado o comportamento da vazão e da pressão do conjunto motobomba diante do sombreamento do arranjo FV iniciado no instante $t=191$ s. Devido a falta de potência do arranjo FV, a partir do instante $t=193 \mathrm{~s}$, o controlador de tensão do conversor CC-CC boost AGT-CCTE não é mais capaz de manter a tensão de saída em 311 V. Para evitar que o conversor de frequência entre em modo de proteção por subtensão, o que ocorre quando a tensão no barramento CC cai abaixo de $200 \mathrm{~V}$, o controlador comanda ao con- 
versor de frequência uma frequência zero sempre que a tensão no barramento CC cair abaixo de $250 \mathrm{~V}$, por precaução. A partir deste momento a tensão do arranjo FV é recuperada devido a redução da carga. Em seguida o controlador reinicia o ciclo de busca pela tensão de máxima potência preestabelecida.
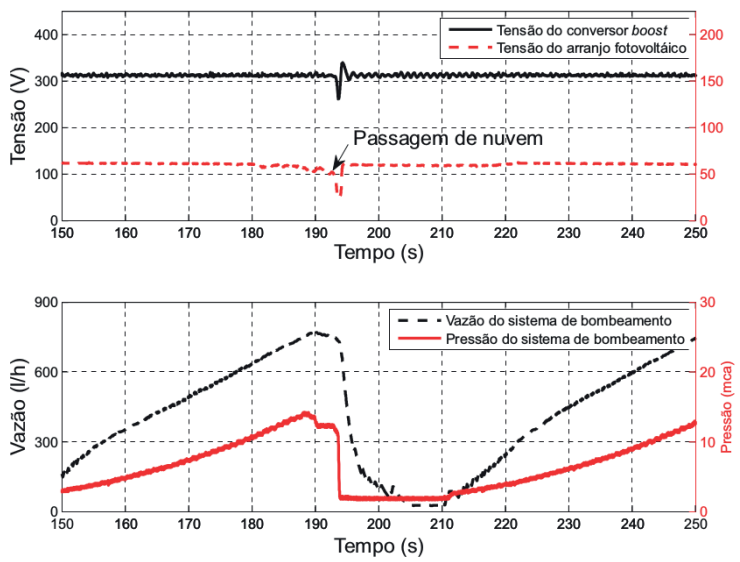

Figura 10: Comportamento da tensão de saída do conversor CC-CC boost diante do sombreamento dos painéis FV.

Na Figura 11 são ilustradas as curvas de rendimento do sistema. Para facilitar a análise dos resultados é utilizado um ganho de 10 para as curvas de rendimento do conjunto conversor CC-CC boost AGT-CCT-conversor de frequência-motobomba e do conjunto conversor de frequência-motobomba.

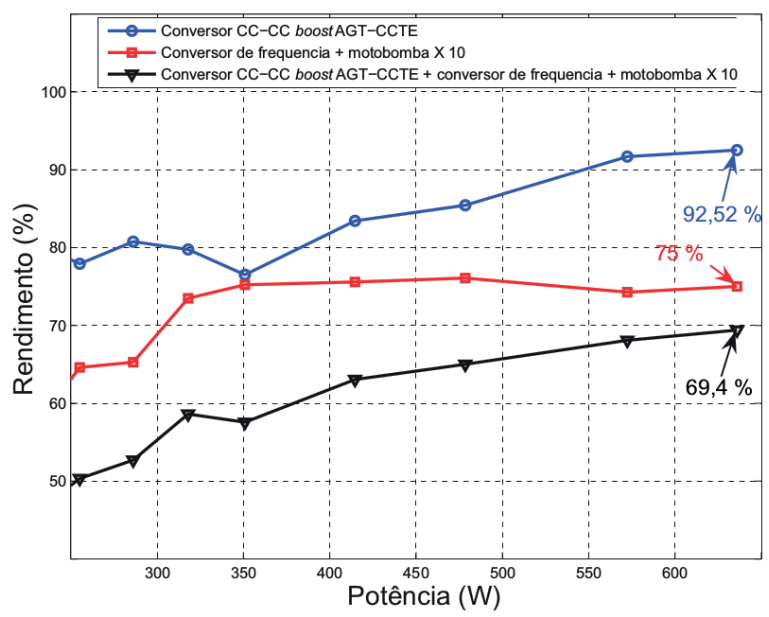

Figura 11: Rendimentos do sistema de bombeamento.

O conversor CC-CC boost AGT-CCTE apresenta uma curva de rendimento crescente com a potência gerada pelos painéis $\mathrm{FV}$, de tal forma que atinge o rendimento de 92,52 \% na condição de 687,42 W gerados. $\mathrm{O}$ rendimento do conjunto conversor de frequênciamotobomba, na condição de máxima potência gerada, atingiu apenas 7,5\%. Informações de catálogo do fabricante do conversor de frequência, juntamente com testes de bancada sugerem que o rendimento do mesmo esteja na ordem de $95 \%$ para operação nominal. No teste realizado, foi obtida uma vazão máxima de 1100 1/h a uma altura manométrica de $25 \mathrm{~m}$.

\section{Conclusões}

O presente trabalho apresenta uma contribuição importante para a implementação de sistemas de bombeamento de água alimentados por painéis $\mathrm{FV}$, uma vez que a utilização de um conversor CC-CC boost possibilita a adequação de potência entre os painéis $\mathrm{FV}$ e o conversor de frequência. No estudo houve também a preocupação de não utilizar baterias, visando dessa forma reduzir os componentes que necessitam de uma manutenção mais especializada.

Com o estudo dos modelos para o conversor CCCC boost AGT-CCTE, é possível concluir que a utilização do modelo de Hammerstein, por utilizar função de transferência como forma de representação para o modelo do conversor em estudo, permitiu a utilização de técnicas convencionais para o projeto do controlador digital.

O conversor CC-CC boost AGT-CCTE utilizado no estudo apresenta-se como alternativa viável para implementação do sistema, devido o mesmo possuir rendimento na ordem de $92,52 \%$, confirmando assim seu rendimento em relação as topologias apresentadas anteriormente.

O sistema demonstra que mesmo diante de variações de irradiância, é capaz de retornar ao funcionamento automaticamente, não havendo desligamentos por subtensão no conversor de frequência. No sistema proposto, as variações observadas de vazão e pressão estão relacionadas diretamente com a irradiância e com a busca da tensão de máxima potência do arranjo fotovoltaico.

\section{REFERÊNCIAS}

AGUIRRE, L. A.; COELHO, M. C. S.; CORREA, $\mathrm{M}$. V. On the interpretation and practice of dynamical differences between hammerstein and wiener models. IEE Proceedings-Control Theory and Applications, IET, v. 152, n. 4, p. 349-356, 2005. 
ALCAZAR, Y. J. A.; BASCOPÉ, R. T.; OLIVEIRA, D. S. de; ANDRADE, E. H.; CÁRDENAS, W. G.

High voltage gain boost converter based on three-state switching cell and voltage multipliers. In: IEEE.

Industrial Electronics, 2008. IECON 2008. 34th Annual Conference of IEEE. Orlando, FL, USA, 2008. p. 2346-2352.

ALCAZAR, Y. J. A.; OLIVEIRA, D. de S.; TOFOLI, F. L.; TORRICO-BASCOPÉ, R. P. Dc-dc nonisolated boost converter based on the three-state switching cell and voltage multiplier cells. IEEE Transactions on Industrial Electronics, IEEE, v. 60, n. 10, p. 4438-4449, 2013.

ALONGE, F.; D'IPPOLITO, F.; RAIMONDI, F. M.; TUMMINARO, S. Nonlinear modeling of dc/dc converters using the hammerstein's approach. IEEE transactions on power electronics, IEEE, v. 22, n. 4, p. 1210-1221, 2007.

ALONGE, F.; RABBENI, R.; PUCCI, M.; VITALE, $\mathrm{G}$. Identification and robust control of a quadratic $\mathrm{dc} / \mathrm{dc}$ boost converter by hammerstein model. IEEE Transactions on Industry Applications, IEEE, v. 51, n. 5, p. 3975-3985, 2015.

ALVES, D. B. S.; PRAÇA, P. P.; OLIVEIRA, D. S.; BARRETO, L. H. S. C.; FREITAS, L. C. G. de. A single-stage three-port boost converter with high voltage gain based on the bidirectional version of the three-state switching cell. In: IEEE. Applied Power Electronics Conference and Exposition (APEC), 2015 IEEE. Charlotte, NC, USA, 2015. p. 1934-1940.

ANEEL. Atlas de energia elétrica do brasil. Brasília, 2005.

BEZERRA, G. R. Modelagem e controle do conversor CC-CC Buck-Boost usando técnicas paramétricas de identificação. Tese (Doutorado) Universidade Federal do Ceará, Ceará, 2015.

BHAT, S.; PITTET, A.; SONDE, B. Performance optimization of induction motor-pump system using photovoltaic energy source. IEEE Transactions on Industry Applications, IEEE, v. 1, n. 6, p. 995-1000, 1987.

BOUTELHIG, A.; BAKELLI, Y. Comparative study on water max a $64 \mathrm{dc}$ pump performances based photovoltaic pumping system design to select the optimum heads in arid area. In: IEEE. Microelectronics (ICM), 2012 24th International Conference on. Algiers, Algeria, 2012. p. 1-5.
BRITO, A.; ZILLES, R. Systematized procedure for parameter characterization of a variable-speed drive used in photovoltaic pumping applications. Progress in Photovoltaics: Research and Applications, Wiley Online Library, v. 14, n. 3, p. 249-260, 2006.

DESSOUKY, S. S.; ELBASET, A. A.; ALABOUDY, A. H. K.; IBRAHIM, H. A.; ABDELWAHAB, S. A. M. Performance improvement of a pv-powered induction-motor-driven water pumping system. In: IEEE. Power Systems Conference (MEPCON), 2016 Eighteenth International Middle East. Cairo, Egypt, 2016. p. 373-379.

DOLJAK, D.; POPOVIĆ, D.; KUZMANOVIĆ, D. Photovoltaic potential of the city of požarevac. Renewable and Sustainable Energy Reviews, Elsevier, v. 73, n. 1, p. 460-467, 2017.

DRAPER, N. R. Applied regression analysis. 1. ed. New York: Wiley, 1998.

GREEN, M. A.; EMERY, K.; HISHIKAWA, Y.; WARTA, W.; DUNLOP, E. D. Solar cell efficiency tables (version 45). Progress in photovoltaics: research and applications, Wiley Online Library, v. 23, n. 1, p. 1-9, 2015.

KLIMCZAK, P.; MUNK-NIELSEN, S. Boost converter with three-state switching cell and integrated magnetics. In: IEEE. Applied Power Electronics Conference and Exposition, 2009. APEC 2009. Twenty-Fourth Annual IEEE. Washington, DC, USA, 2009. p. 1378-1383.

LIU, Y.-H.; HUANG, J.-W. A fast and low cost analog maximum power point tracking method for low power photovoltaic systems. Solar energy, Elsevier, v. 85, n. 11, p. 2771-2780, 2011.

MULJADI, E.; TAYLOR, R. Pv water pumping with a peak power tracker using a simple six step square wave inverter. In: IEEE. Industry Applications Conference, 1996. Thirty-First IAS Annual Meeting, IAS'96., Conference Record of the 1996 IEEE. San Diego, CA, USA, 1996. v. 1, p. 133-142.

PEREIRA, F.; MARTINS, A.; CARVALHO, A. Design of a dc-dc converter with high voltage gain for photovoltaic-based microgeneration. In: IEEE. Industrial Electronics Society, IECON 2014-40th Annual Conference of the IEEE. Dallas, TX, USA, 2014. p. 1404-1409. 
SILVA, R. G. Dimensionamento e levantamento de custos de fontes energéticas, considerando os recursos hídricos para uso em sistemas de bombeamento. Dissertação (Mestrado) Universidade Federal de Uberlândia, Uberlândia, 2014.

SILVEIRA, G. C.; TOFOLI, F. L.; BEZERRA, L. D. S.; TORRICO-BASCOPÉ, R. P. A nonisolated dc-dc boost converter with high voltage gain and balanced output voltage. IEEE Trans. Industrial Electronics, v. 61, n. 12, p. 6739-6746, 2014.

TAHA, M.; SURESH, K. Maximum power point tracking inverter for photovoltaic source pumping applications. In: IEEE. Power Electronics, Drives and Energy Systems for Industrial Growth, 1996., Proceedings of the 1996 International Conference on. New Delhi, India, 1996. v. 2, p. 883-886.

TORRICO-BASCOPÉ, G. V.; VASCONCELOS, S. A.; TORRICO-BASCOPE, R. P.; ANTUNES, F. L.; OLIVEIRA, D. S. D.; BRANCO, C. G. A high step-up dc-dc converter based on three-state switching cell. In: IEEE. Industrial Electronics, 2006 IEEE International Symposium on. Montreal, Que., Canada, 2006. v. 2, p. 998-1003.

WANDERLEY, A. C. Perspectivas de inserção da energia solar fotovoltaica na geração de energia elétrica no Rio Grande do Norte. Dissertação (Mestrado) - Universidade Federal do Rio Grande do Norte, Rio Grande do Norte, 2013. 